\title{
Activated carbon from grass - a green alternative catalyst support for water electrolysis
}

\author{
Kalyani Palanichamy ${ }^{1, *}$, Anitha Ariharaputhiran² Andre Darchen ${ }^{3}$ \\ ${ }^{1}$ Department of Chemistry, Thiagarajar College of Engineering, Madurai 625 015, \\ ${ }^{2}$ Department of Chemistry, SACS MAVMM Engineering College, Madurai 625301. \\ ${ }^{3}$ UMR CNRS No. 6226 Sciences Chimiques de Rennes, ENSCR, Avenue du Général Leclerc, CS \\ 50837, 35708 Rennes Cedex 7, France \\ * Corresponding author. Tel.: +91-452-2482241. \\ E-mail address: pkalyani@tce.edu (P. Kalyani).
}

\begin{abstract}
:
Grass blades (turf grass) have been selected as a cheap biomass source of producing activated carbon for supporting $\mathrm{Pt}$ particles for utilizing as electrocatalyst for $\mathrm{H}_{2}$ generation through electrolysis of water. Activation is done using $\mathrm{ZnCl}_{2}$ followed by thermal processing at $250^{\circ} \mathrm{C} .1 \% \mathrm{Pt}$ was supported over the grass derived activated biomass carbon (G-ABC) powder to result in Pt@GABC. After physical characterization, Pt@G-ABC sample has been tested for its catalytic activity in $1 \mathrm{M}$ sulphuric acid solution for $\mathrm{H}_{2}$ gas generation through Linear Sweep \& Cyclic Voltammetry. Cost factor involved in the production of $\mathrm{G}-\mathrm{ABC}$ has also been compared with the traditional commercially available carbon support. The studies suggest that grass may be considered not only as a potential alternative source for producing carbon supported catalyst for $\mathrm{H}_{2}$ generation but also highlight the production of low-cost carbon for further applications like electrode materials, adsorbent for color, odor and hazardous pollutants.
\end{abstract}

Keywords: grass; activated carbon; catalyst support; electrochemical studies; hydrogen, water electrolysis. 


\section{Introduction}

Hydrogen is a promising energy source and hence significant research is currently being focused to test its feasibility to meet the world energy demand [1, 2]. It is also ideal from an environmental standpoint-it burns cleanly producing water as the only product. Invariably it is stored in nature as water and hydrocarbons and one has to expend energy to generate $\mathrm{H}_{2}$ from

either water or hydrocarbons. A number of production methods including water electrolysis, steam reformation of natural gas, and coal gasification are the foci of widespread production research; but water electrolysis is one of the renowned technologies which provide domestically viable, $\mathrm{CO}_{2}$ neutral and non-polluting $\mathrm{H}_{2}$. Noble metal like Pt or $\mathrm{Ru}$ based electrocatalysts are being employed for producing $\mathrm{H}_{2}$ by electrolyzing water. Generally electrocatalysts are prepared by loading or supporting fine $\mathrm{Pt}$ or $\mathrm{Ru}$ particles on quality carbon powders - the so called catalyst support, such that more number of active sites will be available for efficient and complete electrolysis. In fact carbon black suits well for catalyst support applications [3,4]. Vulcan XC-72 is the most utilized conducting carbon for fabricating electrocatalysts for water electrolysis for hydrogen gas generation [5, 6]. But electrocatalysts are costly, hampering widespread commercialization of water electrolysers. Consequently, there are two directions in which the cost factor can be addressed. Firstly, usage of less noble metal as catalysts and secondly, to use low-cost carbonaceous materials on which the metal particles can be supported. In fact our work aims at achieving the second factor by producing carbon support powders from a cheap and abundantly existing resource namely the biomass of grass blades. Obviously, the significance of adopting different types of biomass materials as starting materials in producing carbon electrodes lies in its abundance, cheap cost, simple and green methodologies in obtaining the carbon and the ability to become highly porous carbon or to get desired physical features after carbonization procedure. 
Carbon materials function as a unique material and are characterized by high specific surface area and tunable porosity just to find utility in many vital technologies namely, energy conversion (fuel cells and solar cells), energy storage (super capacitors, batteries and $\mathrm{H}_{2}$ sorption), sensors, environmental production of fine and bulk chemicals and catalysis [7, 8]. The choice of carbon as the electrode material is because of its unique properties of electrical conductivity and structural diversity. In addition to being good catalyst and catalyst support, carbon materials are effective in removing pollutants (both gaseous and liquid). Further carbon materials being insensitive to toxic substances and corrosive (acidic and basic) environments, its regeneration is possible and easy, rendering the industrial use of carbon materials an economically viable option $[9,10]$. A fact observed by researchers that the specific physico - chemical properties that make carbon materials a potential adsorbent for pollutants are high specific surface area, porous architecture, high adsorption capacity and surface functionality [11]. Carbon consists of a highly porous structure with hydrophobic graphene layer as well as hydrophilic surface functional groups making them beneficial for sorption and catalytic applications.

It is now realized that wastes are unutilized resources. Hence chemical recycling of wastes has been recognized as one of the suitable methods of waste management and also to recover valuable products, the net result is zero-waste world. There have been many attempts to obtain lowcost carbon (activated) from agricultural wastes such as sunflower shell [10], pinecone [12], cotton residues [12], olive residues [12], wheat [13], corn straw 13], olive stones [14, 15], bagasse [14, 15], birch wood [14, 15], miscanthus [14, 15], rapeseed [16], pine rayed [17], eucalyptus maculata [17], sugarcane bagasse [17,18], rice hulls [18], pecan shells [18], grape seeds [19], cherry stones [19], hazelnut shells [20], apricot stones [19, 20], almond shells [19, 21], peach stones [22], straw [14, 15, 23], oat hulls [24, 25], corn stover [24, 25], peanut hull [26], nut shells [19, 27-30], corn cob [22, 31-33], corn hulls [25], rice husks [34, 35], rice straw [18, 36] and used tea refuse [37]. An 
exhaustive report on the various classes of biomasses used for supercapacitor, batteries and fuel cells has been made by the authors of the present paper [38]. Although the above biomass have been utilized as resources for obtaining carbon powders for fabricating electrodes for the aforesaid energy devices, there has been no report on the usefulness of these biomass carbons as a catalyst supporting material. As for the knowledge of the authors of this communication goes, Kang et al [39] describe a method of using grass for obtaining carbon nanotubes. Thus the reports on the utilization of grasses are only limited and so the current work may likely to get attention from researchers working on nonconventional energy sources and environmentalists as well.

Carbons have many advantageous features over metal oxide catalyst supports such as (i) a high specific surface area up to $3000 \mathrm{~m}^{2} \mathrm{~g}^{-1}$, (ii) high stability in acidic and basic media, and (iii) easy recovery of supported metals by burning off the carbon. However, only specific carbon materials belonging to the class of carbon blacks namely Vulcan XC-72 $[5,6]$ and black pearls $2000^{1}$ (both from Cabot Corp.) and activated carbon material viz Nuchar carbon (from MWV corp.) with surface area $1400-1800 \mathrm{~m}^{2} \mathrm{~g}^{-12}$ have been used as catalyst support. Recently, Andersen et al [40] have employed carbon nanofiber and carbon nanotube as catalyst support for PEM fuel cells. So finding conductive carbon support for electrocatalyst is an entirely new concept of research, which has not been reviewed that much elsewhere. Thus for our work we have planned to use hitherto unutilized and novel biomass waste namely grass to convert into active carbons for possible application as conductive support for electrocatalyst for water electrolysis for $\mathrm{H}_{2}$ gas evolution. Our work therefore represents an essential, easy and innovative strategy to produce carbon powders from grass that may have electronic, scientific and industrial applications as conductive support for electrocatalysts for $\mathrm{H}_{2}$ gas generation through electrolysis of water and the results have been presented in a simplified and systematic way. The work also stresses Green Energy from Waste concept, which is the want of the hour. It is to be stated that though there are hundreds of varieties of grasses exist comparison of 
properties of them serves another important and interesting theme of research, but right now it is not our intention.

\footnotetext{
${ }^{1}$ www.cabot.com

${ }^{2} \mathrm{http}: / /$ www.meadwestvaco.com/mwv/groups/content/documents/document/mwv039306.pdf
}

It may be interesting to the readers of this article for the fact that a database called Phyllis containing information on the composition of biomass and wastes is now available at http://www.ecn.nl/phyllis/ constructed at Energy Research Centre of the Netherlands. Phyllis enables making analysis data of individual biomass or waste materials available and offers the possibility to obtain the average composition of any combination of groups and/or subgroups.

\section{Experimental}

\subsection{Preparation of grass derived activated biomass carbon (G-ABC)}

A view of the freshly plucked turf grass bunch can be had from Fig. 1. Mature blades of turf grass bunches were collected from our Institute lawn, washed several times with hot distilled water to remove soil, dust and dirt and were dried under sun shade. The dried grass blades were shredded into small pieces and added to a solution of $\mathrm{ZnCl}_{2}$ taken in the ratio of $1: 1 \mathrm{w} / \mathrm{w}$ of biomass : $\mathrm{ZnCl}_{2}$. The contents were maintained at $60^{\circ} \mathrm{C}$ for 48 hours and finally heat treated at $250^{\circ} \mathrm{C}$ for 2 hours for charring.

The char was washed several times with doubly distilled water until all the $\mathrm{ZnCl}_{2}$ is completely removed. Absence of $\mathrm{Zn}^{2+}, \mathrm{Cl}^{-}$, neutrality in $\mathrm{pH}$ and low conductivity of the washings ensures thorough washing of the sample. The powder was dried in oven and ground. The powder prepared in this way is called grass derived activated biomass carbon (G-ABC). Fig. 2 gives the methodology for producing G-ABC. 


\subsection{Preparation of 1\% Pt on grass derived activated carbon powder (Pt@G-ABC)}

Electrocatalyst powder was prepared by aqueous reduction using $\mathrm{NaBH}_{4}$ as the reducing agent. To prepare 1\% Pt@G-ABC powder, G-ABC powder is first made wet and homogenized with little amount of water and ethanol in a beaker. To this slurry appropriate amount of $\operatorname{Pt}\left(\mathrm{NH}_{3}\right)_{4} \mathrm{Cl}_{2}$ crystals in minimum quantity of water is added drop wise while stirring the contents slowly and thoroughly. Now large excess of $\mathrm{NaBH}_{4}$ solution is added very slowly from a buret while ensuring constant mixing of the contents in the beaker. $\mathrm{NaBH}_{4}$ reduces $\mathrm{Pt}^{2+}$ ions to $\mathrm{Pt}^{0}$ and gets deposited or precipitated over the biomass carbon particles. The beaker is left undisturbed overnight. Completion of reduction with $\mathrm{NaBH}_{4}$ is known by testing an aliquot of the filtrate with $\mathrm{KI}$ solution. Absence of rose coloration with KI shows the complete reduction of Pt ions. The contents are now filtered and washed several times with distilled water until the washing is neutral in $\mathrm{pH}$. The powder is dried and stored in an air-tight container. The above process is explained by the following equation [41].

$$
4\left[\mathrm{Pt}\left(\mathrm{NH}_{3}\right)_{4}\right]^{2+}+\mathrm{NaBH}_{4}+8 \mathrm{OH}^{-} \rightarrow \mathrm{NaBO}_{2}+4 \mathrm{Pt}^{\circ}+16 \mathrm{NH}_{3}+6 \mathrm{H}_{2} \mathrm{O}
$$

The sequence of steps involved in the preparation of 1\% Pt@G-ABC has been shown in Fig. 3.

\subsection{Preparation of electrode for electrochemical studies}

SS rods with circular ends of area $1 \mathrm{~cm}^{2} \& 8 \mathrm{~cm}$ length are employed for fabricating the electrodes. A typical catalyst ink with N-methyl 2 pyrrolidone was obtained by mixing together the $\mathrm{BC}$ powder or $\mathrm{BC}$ supported electro catalyst powder, commercial carbon powder and poly vinylidene fluoride binder in the \% weight ratio 88:10:2 [42] and was applied to the circular end of the SS rods. The electrodes were dried at $80^{\circ} \mathrm{C}$ for 1 hour. Heat shrinkable sleeve was used to mask rest of the electrode portion.

\subsection{Physical characterization and electrochemical tests}

Thermal degradation characteristics of the biomass refuse were studied using thermogravimetry. Experiments were performed on a TGA-50 Analyzer. $2 \mathrm{mg}$ of the sample was 
heated from room temperature to $450^{\circ} \mathrm{C}$ at a ramp rate of $20^{\circ} \mathrm{Cmin}^{-1}$ in air. Powder X-ray diffraction patterns were recorded between $10^{\circ}$ and $80^{\circ}$ on an X'Pert Pro X-ray diffractometer with $\mathrm{CuK}_{\alpha}$ radiation source. The ultimate analysis of the activated carbon was carried out using Vario ELIII CHNS/O Analyzer. Surface area of the G-ABC powder was determined by BET (Brunauer, Emmet and Teller) method using low temperature nitrogen adsorption (Quanta Chrome Nova 1000, US). Surface morphology of the activated carbon was studied using S-3000H model microscope. Density of the activated carbon powder was estimated by Archimedes' principle using xylene [43].

Electro catalytic activity of the activated $\mathrm{BC}$ as well as the supported electro catalyst powder samples were assessed by performing liner sweep voltammetric and cyclic voltammetric studies (on Zahner electrochemical measurement unit; model No. IM6e) with the test cells assembled using SS rod loaded catalyst powder (or virgin carbon) as the working electrode, Saturated Calomel Electrode as the reference and a Pt wire $(1 \mathrm{~mm}$ diameter) as the counter electrode. The electrochemical measurements (linear sweep and cyclic voltammetry) made to evaluate the catalytic activity of the samples were carried out in de-aerated $1 \mathrm{M} \mathrm{H}_{2} \mathrm{SO}_{4}$ electrolyte. Electrode surfaces were first activated by cycling in the potential range of -0.2 to $+1.1 \mathrm{~V}$ vs. SCE, in order to obtain stable and reproducible voltammograms.

\section{Results and Discussion}

\subsection{Burn-off}

Conversion of grass biomass in to biomass carbon took place around $250^{\circ} \mathrm{C}$, also corroborated through TGA studies and the weight of the char was noted to calculate the yield (burn-off). Since the biomass was heated in a furnace a significant amount of carbon content might have been converted as $\mathrm{CO}_{2}$. Hence the yield is expected to be less and as expected the yield was only $46 \%$. Higher yields could have been obtained if the samples were heated in an inert atmosphere. 


\subsection{Thermogravimetric (TG) Analysis}

Thermal degradation characteristics of the grass sample (dried mass) were studied using thermogravimetry. Around $2 \mathrm{mg}$ of the sample was heated from room temperature to $400^{\circ} \mathrm{C}$ at a heating rate of $10^{\circ} \mathrm{Cmin}^{-1}$ under air atmosphere. The thermogram of the dried grass revealed that major decomposition occurred between $250-310^{\circ} \mathrm{C}$ as shown in the Fig. 4 . The weight loss around $52 \%$ may be due to the escape of decomposition products like moisture, $\mathrm{CO}_{2}$, oxides of nitrogen and volatile organic compounds.

\subsection{Ultimate analysis}

Ultimate analysis report of the G-ABC sample shows $76.66 \% \mathrm{C}, 0.211 \% \mathrm{~N}, 0.011 \% \mathrm{~S} \&$ $1.253 \% \mathrm{H}$ and balance oxygen. Due to the preferential loss of $\mathrm{H}$ and $\mathrm{O}$ with heating, carbon concentration and degree of aromatisation may increase with pyrolysis. Significant \% of N, S \& $\mathrm{H}$ in the sample shows the presence of various organic functional groups. Fourier Transform Infra Red (FT-IR) data also bears support for these organic functional groups, the presence of which is expected to influence the electrochemical behavior of the carbon samples prepared.

\subsection{Powder X-ray diffraction (PXRD) studies}

X-ray diffraction patterns of the G-ABC and 1\% Pt@G-ABC powders have been depicted in Fig. 5 and as an inset in Fig. 5. The appearance of a broad peak around $24^{\circ}$ in the XRD of the G$\mathrm{ABC}$ indicates the presence of microporous carbon and the microporous structure is amorphous carbon in nature with non-crystalline structures [44]. More precisely, disordered single graphene layers and stacked structures of graphene sheets may be present simultaneously in the texture of the carbon powder [45] and the broad shape indicates highly disordered structure in the carbon [46]. However the strong peaks in the middle of the humps suggest that an organized crystalline structure exists in the amorphous carbon structure of grass. The interplanar space $\left(\mathrm{d}_{002}\right)$ calculated for the 
virgin carbon is $4.03 \AA$, larger than that observed for graphite $(3.354 \AA)$ indicating considerable disorderliness in the carbon produced [47-49]. Generally the value of $\mathrm{d}_{002}$ is taken as a measure of estimating the degree of graphitization in the carbon and growing disorder is reflected in larger values of $\mathrm{d}_{002}$. Changes in the PXRD pattern of the Pt@G-ABC show the modification due to Pt particles on the grass. (111) \& (200) peaks of Pt are observed (given as inset in Fig. 5) and it is a fact that the (002) peak of carbon is found to be suppressed here, revealing predominant and homogeneous existence of Pt particles over the entire carbon surface.

\subsection{FT-IR vibrational studies}

The electrochemical properties of activated carbon depend upon the physical properties as well as the nature and chemical reactivity of the functional groups present on the carbon surface. Knowledge on surface functional groups would give insight to the electrochemical properties of the activated carbon. FT-IR data was collected for qualitative characterization of the surface functional groups of the activated carbon samples and is presented in Fig. 6. Various FT-IR signatures observed and respective assignment is given in Table 1. An analysis of the table 1 shows the presence of $\mathrm{COOH}, \mathrm{OH}$, nitro and $\mathrm{C}-\mathrm{H}$ bonds on the surface of the activated carbon samples. These organic functionalities may help in the anchorage Pt particles throughout the carbon surface uniformly. Also these polar groups are expected to impart hydrophilicity to the electrode, paving way for the easy accessibility of the electrolyte in to the

pores of the electrode particles, thus facilitating efficient electrolysis of water. Further, the absence of a peak around $3400 \mathrm{~cm}^{-1}$ shows the evident absence of amino group. So the nitrogen present in the sample may probably due to nitro group. Subramanian et. al. [50] have reported that the organic groups with oxygen, typically, phenols, carbonyls, lactones, quinine and quinine-like structures are expected to form on the surface during the thermal treatment of the biomass precursors and may appear at the edge carbon atoms. This fact may also be applied to grass samples and the effect or 
mechanism of action of these organics on the electroactivity/catalytic activity of the carbon samples may be complex and forms an exclusive research object. The presence of Pt over the carbon surface or the coordination of Pt with the organic functional groups can be confirmed only when FT-IR spectrum is recorded down to $300 \mathrm{~cm}^{-1}$, which is out of our reach as of now.

\subsection{Scanning electron microscopic (SEM) studies, Surface area $\left(\mathrm{S}_{\mathrm{BET}}\right)$ and density measurements}

The SEM image of G-ABC is shown in the Fig. 7. It is observed that the carbon particles are of irregular size and ununiformly distributed. Also the particles appear as layers stacked or bundled together. The particles seem to lack porosity and hence it is not possible to offer any correlation between the particle morphology and the electrochemical activity as of now. Surface area of the G$\mathrm{ABC}$ carbon sample was found to be $1201 \mathrm{~m}^{2} \mathrm{~g}^{-1}$. The surface area of G-ABC is observed to be higher than the commonly employed carbon support namely Vulcan XC-72 which has the value of around $250 \mathrm{~m}^{2} \mathrm{~g}^{-1}$ [5]. High surface area may be indicative of the presence of enormous electrochemically accessible sites or area thereby resulting in increased catalytic activity to the Pt@G-ABC ultimately. It is to be mentioned that surface functionalities would not be altered as a result of activating the sample and hence for these reasons the authors expect that the catalytic activity observed for the Pt@G-ABC sample may be due to the improved surface area.

Density of coconut, lignite, wood and coal activated carbon samples reported in the literature is in the range of $0.35-0.48 \mathrm{gcc}^{-13}$ while our G-ABC sample has density of $0.77 \mathrm{gcc}^{-1}$, a value higher than that of those seen above. It may convince the readers that the high density value might be the result of the presence of significant amount of $\mathrm{O}$ and $\mathrm{N}$ in our samples. But the notion that grass contains enormous cellulose fibers and hence carbon material obtained from the thermal treatment of fibrous precursor would be lighter, resulting in fibrous and porous carbon structure. Though this feature is not directly evident from SEM given in Fig. 7, it can still be 
presumed that the individual stack or bundle may be fibrous and porous based on the density criteria. Further, higher density provides greater volume activity and normally indicates better quality activated carbon ${ }^{4}$.

${ }^{3} \mathrm{http}: / /$ www.carbochem.com/activatedcarbon101.html.

${ }^{4}$ http://en.wikipedia.org/wiki/Activated_carbon.html.

\section{Results of electrochemical or electrocatalytic characterization studies}

\subsection{Linear Sweep Voltammetric (LSV) studies}

LSV study is undertaken to have an idea on the voltage at which $\mathrm{H}_{2}$ gas evolution occurs from water. LSV plot of G-ABC \& Pt@G-ABC electrodes are displayed in the Figs. 8 set. Voltage of the working electrode was swept from $0.0 \mathrm{~V}$ to $-0.4 \mathrm{~V}$ Vs SCE at a scan rate of $20 \mathrm{mVsec}^{-1}$. Fig. 8. LSV plot of (a) G-ABC \& (b) 1\% Pt@G-ABC electrodes in $1 \mathrm{M} \mathrm{H}_{2} \mathrm{SO}_{4}$. Water decomposition setting in at $-0.24 \mathrm{~V}$ Vs SCE for 1\% Pt@G-ABC is indicated in Fig. 8b and the rate of increase in current density is very much rapid with this electrocatalyst. For G-ABC no activity is observed since current density is comparatively less (Fig. 8a). The results suggest that the remarkable increase in the current density causes enhanced $\mathrm{H}_{2}$ evolution (at lower voltages) when Pt@G-ABC catalyst is used.

\subsection{Cyclic voltammetric (CV) studies}

CV of the G-ABC \& 1\% Pt@G-ABC samples is presented respectively in Figs. 9a \& b set. $\mathrm{CV}$ was recorded between -0.4 to $+1.0 \mathrm{~V}$ at a sweep rate of $20 \mathrm{mVsec}^{-1}$. LSV and CV offer almost the same results as far as our study is concerned. These experiments are valuable in letting us know the better performing biomass carbon sample(s) based electrocatalysts. The rate of change of 
current density is taken as an index to measure the catalytic activity of the electrodes studied. No change in the current density and hence no electrochemical or catalytic activity with G-ABC (Fig. 9a) is observed while $\mathrm{H}_{2}$ evolution is noticed around -0.2 V Vs SCE in Pt@G-ABC (indicated as “**” in the Fig. 9b). Oxidation of organic moieties of $\mathrm{Pt} @ \mathrm{G}-\mathrm{ABC}$ is also observed at positive potentials (indicated as “*” in Fig. 9b). A similar type of pattern of CV has been observed by Murakami et al [51] in their studies with perchloric acid electrolyte. Interestingly, rapid change in the current density is observed only in the Pt case. The improvement in the catalytic activity of Pt@G-ABC over G$\mathrm{ABC}$ may be attributed to the physical nature and the high active surface area of the sample powders activated with $\mathrm{ZnCl}_{2}$. It can thus be regarded that the $\mathrm{ZnCl}_{2}$ activated $\mathrm{G}-\mathrm{ABC}$ powder may be useful as a conductive material for supporting electrocatalyst particles and undoubtedly, $1 \% \mathrm{Pt}$ supported on activated carbon derived from grass blades emerge as one of the candidates of choice for $\mathrm{H}_{2}$ gas evolution from acid electrolysis. This is established through various electrochemical studies with respect to electrocatalyzed $\mathrm{H}_{2}$ gas generation by water electrolysis. This is considered as the prime novelty of our studies. It is to be stressed that commercial electrocatalysts contain $10 \%$ or higher Pt content supported on carbon and so the authors presume that 10\% Pt@G-ABC would be definitely as good as the commercial ones or even better. Hence it is worth performing comparative studies with the commercial electrocatalysts supported on conducting carbon but has been reserved for the future.

Furthermore, an analysis of the cost of obtaining G-ABC and that of the most popular and commercially available Vulcan XC-72 and 10\% Pt supported on Vulcan XC-72 both from Cabot Corp. is valid and has been presented here. The intention is that the findings of the cost analysis will influence the evolution of future research activities elsewhere involving grass or any other biomass for obtaining carbon supported catalysts. The cost of Vulcan XC-72 from Cabot Corp. is reported to be USD 20.00 per $250 \mathrm{~g}$ and that of $10 \% \mathrm{Pt}$ on Vulcan-XC-72 is USD 56.00 per gram ${ }^{5}$. Although G- 
$\mathrm{ABC}$ can be obtained from zero-cost biomass commercial success could be achieved only if electrode structures, pore volume, particle distribution and electrode stability during hydrogen generation in

$\overline{5 \text { www. fuelcellstore.com }}$

water electrolysers are optimized. However, our preliminary investigation suggests that G-ABC may be a better alternative to the traditional carbon supports in the near future.

The authors of the present article has extended similar type of studies with activated carbon derived from other biomass such as calotropis stem, palm leaves, coconut leaves etc. Since the physical features and chemical constituents influence the electrochemical or the catalytic properties we have diversified choice of sources of biomass carbon for utilizing as electrocatalyst conductive supports. Hence research may be oriented towards this area which could lead to carbon powders with unexpected properties tunable to the applications.

To summarize, we have described how biomass carbon powder from GREEN biomass waste namely GRASS can be produced and attempted to evaluate its potential as a conductive support for electrocatalysts for the electro-generation of $\mathrm{H}_{2}$ gas from acidified water. Electrocatalyst powder samples are prepared using the thus produced biomass carbon supports with 1\% Pt loading (Pt@G$A B C)$. Further applications of the biomass carbon supported electrocatalyst powder samples obtained through this work have also been highlighted.

1. The work is based on Waste-to-Energy concept.

2. The work focuses on preparing low-cost conductive carbon for supporting electrocatalyst for the electrochemical generation of $\mathrm{H}_{2}$ gas from water using GREEN BIOMASS namely GRASS! (turf grass)

3. Activated Carbon powders from the grass was obtained by chemical activation with $\mathrm{ZnCl}_{2}$ 
4. Catalyst powders of $1 \%$ wt Pt was successfully supported on the carbon produced from the grasses by an aqueous reduction using $\mathrm{NaBH}_{4}$

5. Physical features of the catalyst powders was evaluated through various instrumental techniques like PXRD, FTIR, density, SEM, surface area

6. Electrochemical or catalytic activity of the biomass carbon supported catalyst powders assessed by LSV \& CV studies

7. $\mathrm{H}_{2}$ gas liberation activity of $1 \% \mathrm{Pt}$ supported on grass derived carbon is apparently good

\section{Conclusion}

The work shows how environmental wastes could be a useful source of obtaining novel engineering material like activated carbon or in other words, biomass carbon. In the present work grasses are considered as a safer, cheaper and greener way of utilizing them as a source of preparing activated carbon as well as conductive support for noble metal electrocatalysts. Even 1\% Pt@G$\mathrm{ABC}$ has been found to enhance the $\mathrm{H}_{2}$ generation rate through electrolysis of acidified water remarkably. In our studies current density has been taken as the index of evaluating the catalytic activity of the samples. $\mathrm{H}_{2}$ evolution from water catalyzed by 1\% Pt@G-ABC was observed around -

$0.24 \mathrm{~V}$ Vs SCE and the good performance of the same may be due to high \% carbon content, favorable physical properties \& uniform dispersion of Pt particles on G-ABC powder. Thus grass derived carbon could be an appropriate low-cost alternative to the conventional carbon supports for electrocatalysts for the renewable source of hydrogen gas. The developed electrocatalysts could be used in proton exchange membrane fuel cells as well and many other applications indicated in the previous section. The objective and the fundamental experimental results presented here would break through not only the limits of carbon sources but also the conventional idea of obtaining active carbon and then applying them into various technologies where carbon is vital. 


\section{Acknowledgments}

The authors thank The Management of Thiagarajar College of Engineering, Madurai and the experts at acknowledgment various R \& D institutions for helping in instrumental analysis. The authors sincerely thank the reviewers for the critical evaluation of the MS.

\section{References}

[1] B. Sakintuna, F. Lamari-Darkrim, M. Hirscher, Metal hydride materials for solid hydrogen storage: A review, Int. J. Hydrogen Energ. 32 (2007) 1121.

[2] M. Balat, Potential importance of hydrogen as a future solution to environmental and transportation problems, Int. J. Hydrogen Energ. 33 (2008) 4013.

[3] Roskill, The economics of Activated Carbon, third ed., Roskill Information Services Limited, London, 1990.

[4] J.B. Donnet, R.C. Bansal, F. Stoeckli, Carbon Fibers, second ed., Marcel Dekker, New York, 1990.

[5] S.A. Grigoriev, P. Millet b, V.N. Fateev, Evaluation of carbon-supported Pt and Pd nanoparticles for the hydrogen evolution reaction in PEM water electrolysers, Journal of Power Sources 177 (2008) 281-285.

[6] J. Prabhuram, T.S. Zhao, C.W. Wong, J.W. Guo, Synthesis and physical/electrochemical characterization of $\mathrm{Pt} / \mathrm{C}$ nanocatalyst for polymer electrolyte fuel cells, Journal of Power Sources 134 (2004) 1-6.

[7] M. Endo, C. Kim, K. Nishimura, T. Fujino, K. Miyashita, Recent development of carbon materials for Li ion batteries, Carbon 28 (2000) 183.

[8] A.L. Dicks, The role of carbon in fuel cells, J. Power Sources 156 (2006) 128. 
[9] X. Wang, N. Zhu, B. Yin, Preparation of sludge-based activated carbon and its application in dye wastewater treatment, J. Hazard. Mater. 153 (2008) 22.

[10] X. Chen, S. Jeyaseelan, N. Graham, Physical and chemical properties study of the activated carbon made from sewage sludge, Waste Manage. 22 (2002) 755.

[11] Z. Merzougui, F. Addoun, Effect of oxidant treatment of date pit activated carbons application to the treatment of waters, Desalination 222 (2008) 394.

[12] H. Haykiri-Acma, S. Yaman, S. Kucukbayrak, Gasification of biomass chars in steam-nitrogen mixture, Energy Convers. Manage. 47 (2005) 1004.

[13] M. Lanzetta, C.Di Blasi, Pyrolysis kinetics of wheat and corn straw, J. Anal. Appl. Pyrol. 44 (1998) 181.

[14] V. Minkova, M. Razvigorova, E. Bjornbom, R. Zanzi, T. Budinova, N. Petrov, Effect of water vapour and biomass nature on the yield and quality of the pyrolysis products from biomass, Fuel Proc. Technol. 70 (2001) 53.

[15] V. Minkova, S.P. Marinov, R. Zanzi, E. Bjornbom, T. Budinova, M. Stefanova, et al., Thermochemical treatment of biomass in a flow of steam or in a mixture of steam and carbon dioxide, Fuel Proc. Technol. 62 (2000) 45.

[16] M. Predel, W. Kaminsky, Pyrolysis of rape-seed in a fluidized-bed reactor, Bioresource Technol. $66(1998) 113$.

[17] E. Cetin, B. Moghtaderi, R. Gupta, T.F. Wall, Influence of pyrolysis conditions on the structure and gasification reactivity of biomass chars, Fuel 83 (2004) 2139.

[18] M. Ahmedna, W.E. Marshall, R.M. Rao, Production of granular activated carbons from select agricultural byproducts and evaluation of their physical, chemical and adsorption properties, Bioresource Technol. 71 (2000) 113. 
[19] D. Savova, E. Apak, E. Ekinci, F. Yardim, N. Petrova, T. Budinova, et al., Biomass conversion to carbon adsorbents and gas, Biomass Bioenerg. 21 (2001) 133.

[20] A. Aygun, S. Yenisoy-Karakas, I. Duman, Production of granular activated carbon from fruit stones and nutshells and evaluation of their physical, chemical and adsorption properties, Micropor. Mesopor. Mater. 66 (2003) 189.

[21] A. Marcilla, S. Garcia-Garcia, M. Asensio, J.A. Conesa, Influence of thermal treatment regime on the density and reactivity of activated carbons from almond shells, Carbon 38 (2000) 429 .

[22] W.T. Tsai, C.Y. Chang, S.L Lee, Preparation and characterization of activated carbons from corn cob, Carbon 35 (1997) 1198.

[23] P.A. Jensen, B. Sander, K. Dam-Johansen, Pretreatment of straw for power production by pyrolysis and char wash, Biomass Bioenerg. 20 (2001) 431.

[24] M. Fan, W. Marshall, D. Daugaard, R.C Brown, Steam activation of chars produced from oat hulls and corn stover, Bioresource Technol. 93 (2004) 103.

[25] T. Zhang, W.P. Walawender, L.T. Fan, M. Fan, D. Daugaard, R.C. Brown, Preparation of activated carbon from forest and agricultural residues through $\mathrm{CO}_{2}$ activation, Chem. Eng. J. 105 (2004) 53.

[26] B.S Girgis, S.S. Yunis, A.M. Soliman, Characteristics of activated carbon from peanut hulls in relation to conditions of preparation, Mater. Lett. 57 (2002) 164.

[27] A.C Lua, T. Yang, J. Guo, Effects of pyrolysis conditions on the properties of activated carbons prepared from pistachio-nut shells, J. Anal. Appl. Pyrol. 72 (2004) 279.

[28] A. Ahmadroup, D.D. Do, The preparation of activated carbon from macadamia nutshell by chemical activation, Carbon 35 (1997) 1723.

[29] T. Yang, A.C. Lua, Characteristics of activated carbons prepared from pistachio-nut shells by physical activation, J. Colloid Interf. Sci. 267 (2003) 408. 
[30] M. Ahmedna, W.E. Marshall, A.A. Husseiny, R.M. Rao, I. Goktepe, The use of nutshell carbons in drinking water filters for removal of trace metals, Water Res. 38 (2004) 1062.

[31] W.T. Tsai, C.Y. Chang, S.L. Lee, A low cost adsorbent from agricultural waste corn cob by zinc chloride activation, Bioresource Technol. 64 (1998) 211.

[32] W.T. Tsai, C.Y. Chang, S.Y. Wang, C.F. Chang, S.F. Chien, H.F. Sun, Cleaner production of carbon adsorbents by utilizing agricultural waste corn cob, Resour. Conserv. Recy. 32 (2001) 43.

[33] A-N.A. El-Hendawy, S.E. Samra, B.S. Girgis, Adsorption characteristics of activated carbons obtained from corncobs, Colloid Surface A: Physicochem. Eng. Aspects A 180 (2001) 209.

[34] P.K. Malik, Use of activated carbons prepared from sawdust and rice-husk for adsorption of acid dyes: a case study of Acid Yellow 36, Dyes Pigments 56 (2003) 239.

[35] N. Yalcin, V. Sevinc, Studies of the surface area and porosity of activated carbons prepared from rice husks, Carbon 38 (2008) 1943.

[36] G.H. Oh, C.R. Park, Preparation and characteristics of rice-straw-based porous carbons with high adsorption capacity, Fuel 81 (2002) 327.

[37] P. Kalyani, A. Anitha, Tea derived boric acid activated biomass carbon: Prospects as low-cost electrodes for capacitors, Submitted to Chem. Engg. J. (May 2013).

[38] P. Kalyani, A. Anitha, Biomass carbon \& its prospects in electrochemical energy systems, Int. J. Hydrogen Ener. 38 (2013) 4034-4045.

[39] Z. Kang, E.Wang, B. Mao, Z. Su, L. Chen, L. Xu, Obtaining carbon nanotubes from grass, Nanotechnology 16 (2005) 1192.

[40] Shuang Ma Andersen, Maryam Borghei, Peter Lund, Yli-Rantala Elin, Antti Pasanen, Esko Kauppinen et al, Durability of carbon nanofiber (CNF) \& carbon nanotube (CNT) as catalyst support for Proton Exchange Membrane Fuel Cells,Solid State Ionics 231 (2013) 94-101. 
[41] P. Millet, F. Andolfatto, F. Durand, Preparation of solid polymer electrolyte composites: investigation of the precipitation process, J. Appl. Electrochem. 25 (1995) 233.

[42] P. Kalyani, N. Kalaiselvi, N. Muniyandi, A new solution combustion route to synthesize $\mathrm{LiCoO}_{2}$ and $\mathrm{LiMn}_{2} \mathrm{O}_{4}$, J. Power Sources 111 (2002) 232.

[43] Annual Book of ASTM Standards, vol. 2, no. 5, Philadelphia, USA, 1989, pp. B527.

[44] R. Alcantara, G.F. Ortiz, P. Lavela, J.L. Tirado, EPR, NMR, and electrochemical studies of surface-modified carbon microbeads, Chem. Mater. 18 (2006) 2293.

[45] Y. Zhang, F. Zhang, G.D. Li, J.S. Chen, Microporous carbon derived from pinecone hull as anode material for lithium secondary batteries, Materials Lett. 61 (2007) 5209. [46] J.R. Dahn, A.K. Singh, H. Shi, J.N. Reimers, Q. Zhong, B.M. Way, Dependence of the electrochemical intercalation of lithium in carbons on the crystal structure of the carbon, Electrochim. Acta 38 (1993) 1179.

[47] T. Kyotani, T. Nagai, S. Inoue, A. Tomita, Formation of new type of porous carbon by carbonization in zeolite nanochannels, Chem. Mater. 9 (1997) 609.

[48] A. Cuesta, P. Dhamelincourt, J. Laureyns, A. Martínez-Alonso, J.M.D. Tascon, Comparative performance of X-ray diffraction and Raman microprobe techniques for the study of carbon materials, J. Mater. Chem. 8 (1998) 2875.

[49] Z .Wang, Z. Lu, Y. Huang, R. Xue, X. Huang, L. Chen, Characterizations of crystalline structure and electrical properties of pyrolyzed polyfurfuryl alcohol, J. Appl. Phys. 82 (1997) 5705.

[50] V. Subramanian, C. Luo, A.M. Stephan, K.S. Nahm, Sabu Thomas, Bingqing Wei, Supercapacitors from Activated Carbon Derived from Banana Fibers, J. Phys. Chem. C 111 (2007) 7527. 
[51] Y. Murakami, K. Esumi, H. Honda, Preparation and characterization of an electrocatalytic electrode using amphiphilic carbonaceous material containing metal compound, Carbon 34 (1996) 463-470.

\section{FIGURE CAPTIONS}

Fig. 1. A view of turf grass bunch.

Fig. 2. Flow sheet for the preparation of G-ABC.

Fig. 3. Flow sheet for preparing Pt particles supported on G-ABC (Pt@G-ABC).

Fig. 4. Thermogram of dried grass sample.

Fig. 5. Powder XRD of G-ABC sample. Inset: XRD of 1\% Pt@G-ABC.

Fig. 6. FT-IR spectrum of G-ABC.

Fig. 7. SEM of G-ABC.

Fig. 8. LSV plot of (a) G-ABC \& (b) 1\% Pt@G-ABC electrodes in $1 \mathrm{M} \mathrm{H}_{2} \mathrm{SO}_{4}$.

Fig. 9. CV of (a) G-ABC \& (b) Pt@G-ABC electrodes in $1 \mathrm{M} \mathrm{H}_{2} \mathrm{SO}_{4}$.

\section{TABLE CAPTIONS}

Table 1. FT-IR spectral data on G-ABC. 
Table 1 FTIR spectral data on G-ABC.

\begin{tabular}{cl}
\hline IR frequency $\left(\mathrm{cm}^{-1}\right)$ & \\
3731 & Free $\mathrm{O}-\mathrm{H}$ groups \\
2464 & $\mathrm{O}-\mathrm{H}$ stretch from strongly H-bonded $-\mathrm{COOH}$ group \\
2913 & $\mathrm{O}-\mathrm{H}$ stretching of $-\mathrm{COOH}$ group \\
1713 & Free $-\mathrm{C}-\mathrm{O}$ group stretching \\
1562 & Carboxylate anion stretching \& $\mathrm{NO}_{2}$ group \\
1222 & $\mathrm{C}-\mathrm{N}$ stretching \\
1377 & $\mathrm{C}=\mathrm{N}$ stretching \\
1055 & $\mathrm{C}-\mathrm{C}$ stretching \\
$1498 \& 1402$ & $\mathrm{C}-\mathrm{H}$ bending \\
\hline
\end{tabular}




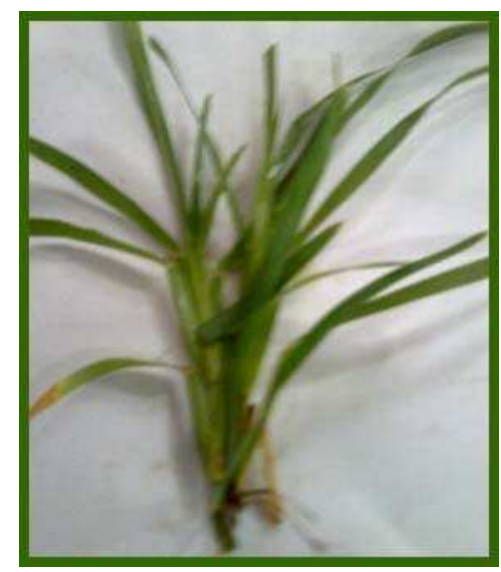

Fig. 1. A view of turf grass bunch.

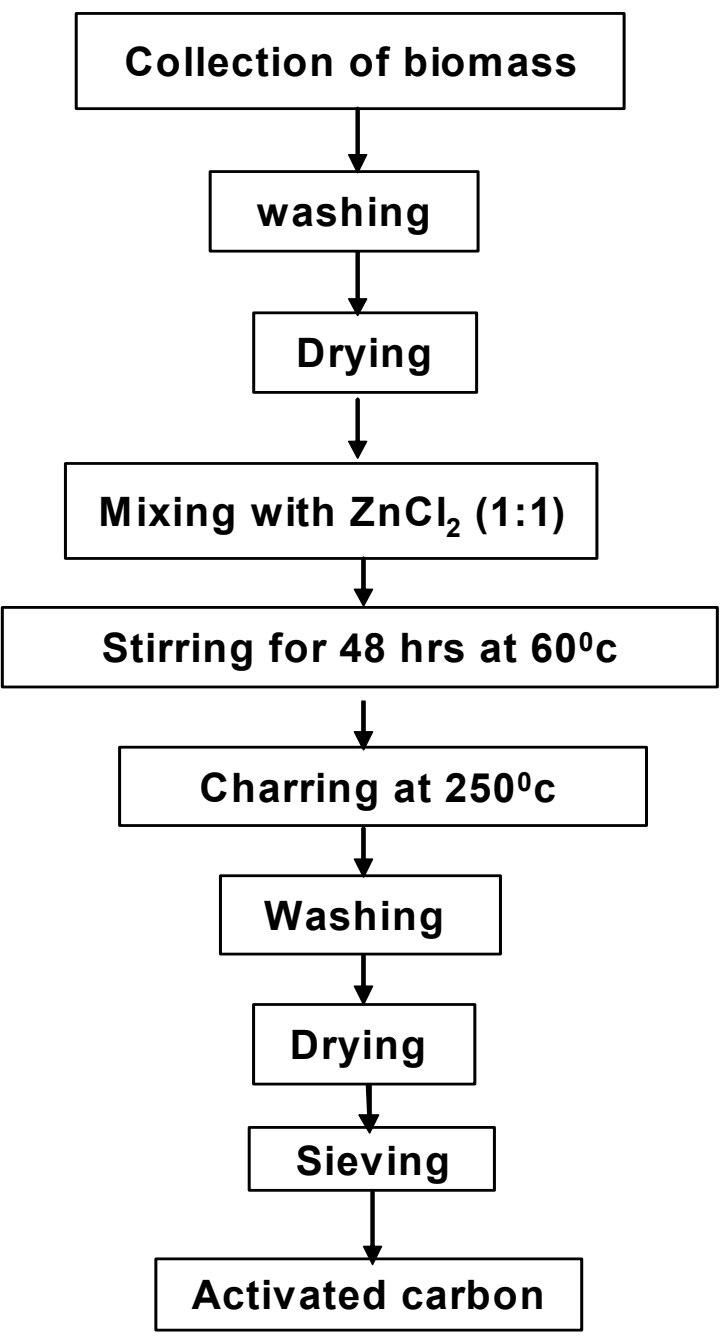

Fig. 2. Flow sheet for the preparation of activated carbon from grass blades (G-ABC). 


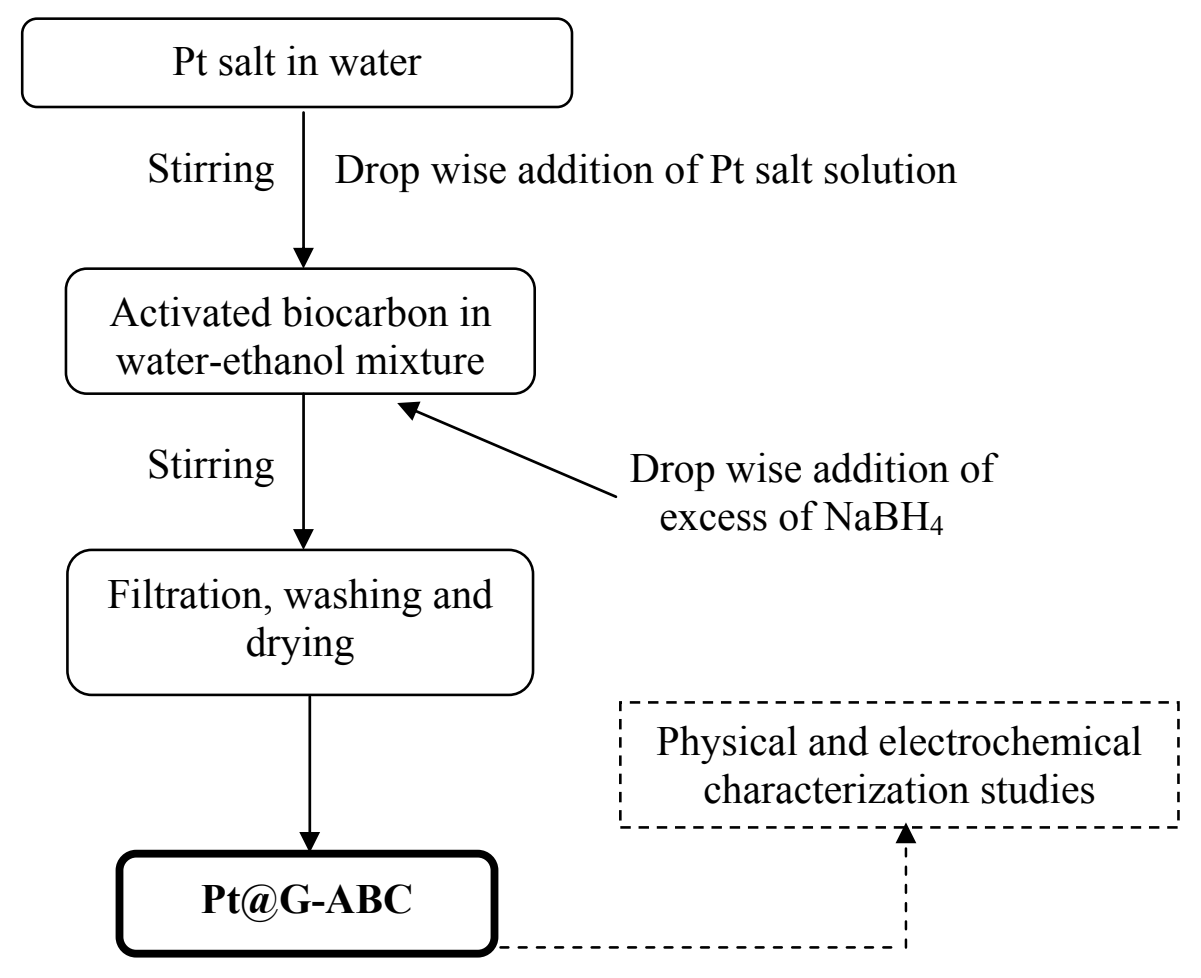

Fig. 3. Flow sheet for preparing Pt particles supported on G-ABC (Pt@G-ABC).

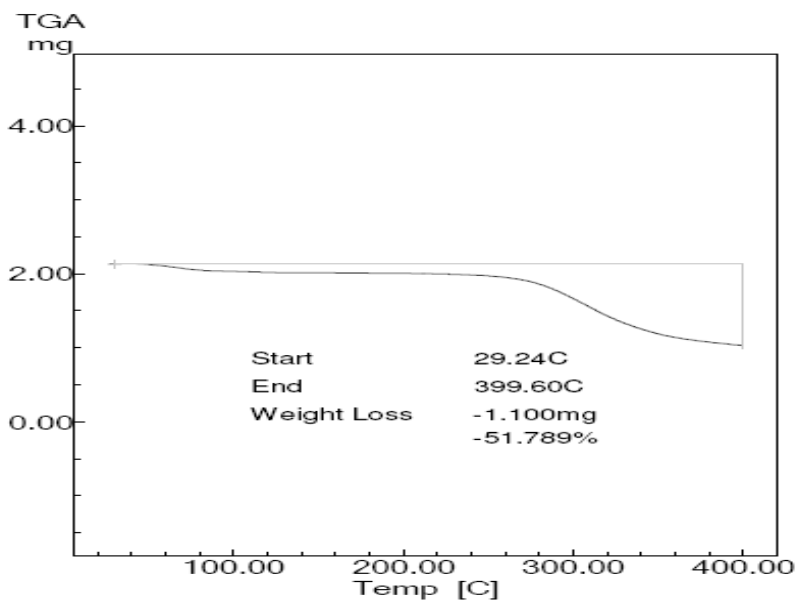

Fig. 4. TG of dried grass sample. 


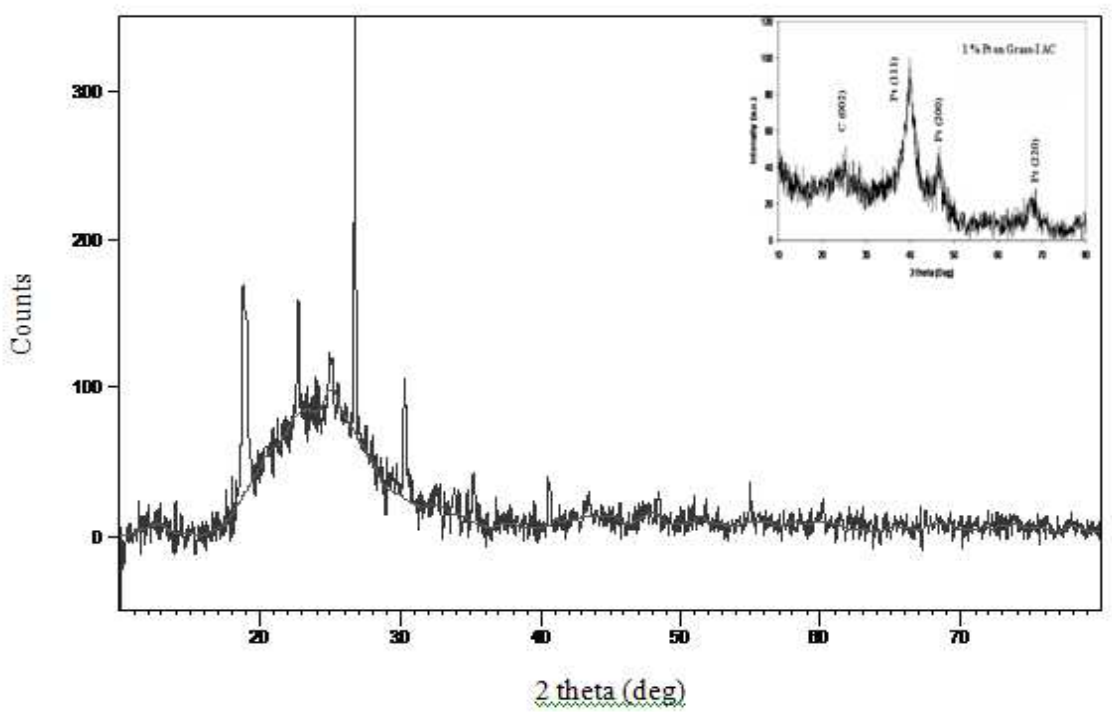

Fig. 5. Powder XRD of G-ABC sample. Inset: XRD of 1\% Pt@G-ABC.

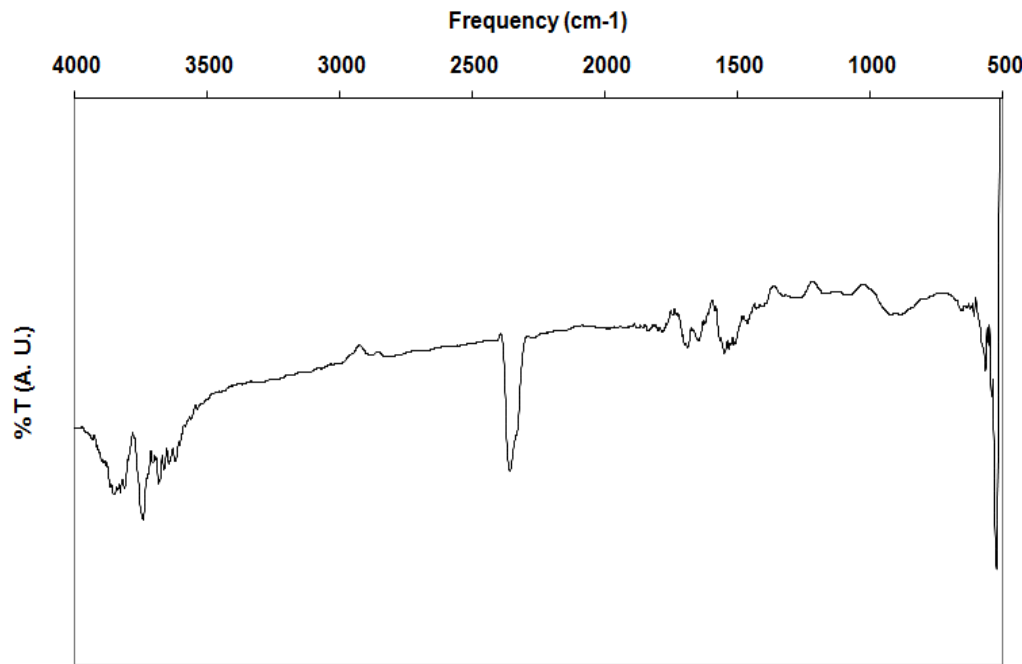

Fig. 6. FTIR spectrum of G-ABC.

Magnification : X 1200

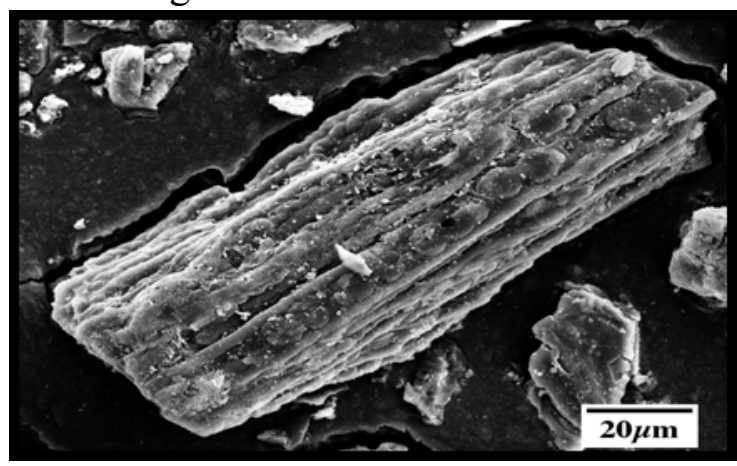

Fig. 7. SEM of G-ABC. 

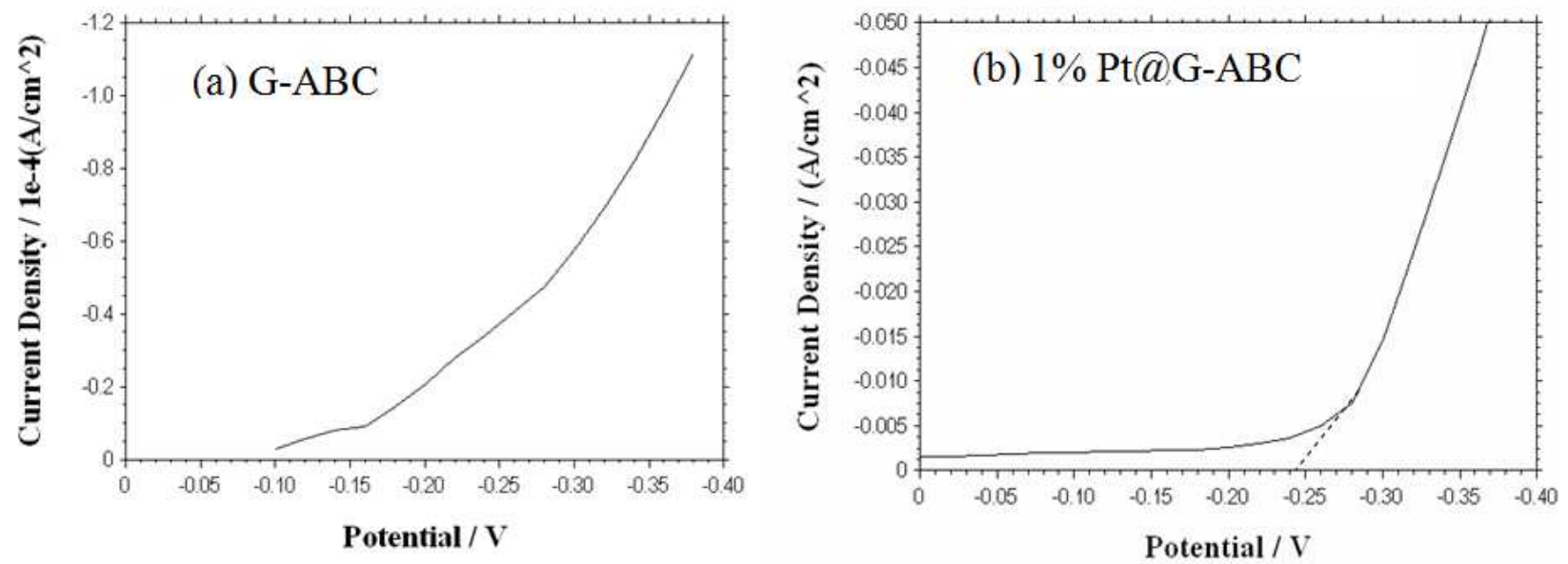

Fig. 8. LSV plot of (a) G-ABC \& (b) 1\% Pt@G-ABC electrodes in $1 \mathrm{M} \mathrm{H}_{2} \mathrm{SO}_{4}$.
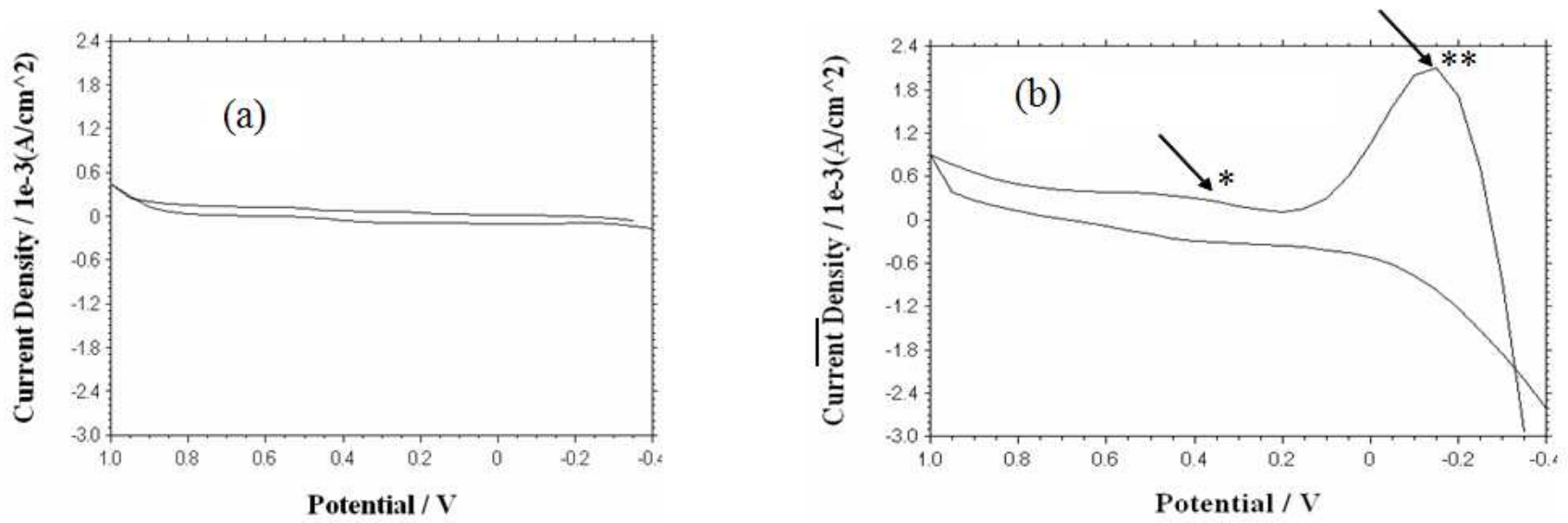

Fig. 9. CV of (a) G-ABC \& (b) Pt@G-ABC electrodes in $1 \mathrm{M} \mathrm{H}_{2} \mathrm{SO}_{4}$. 